\title{
Analytical and numerical research of equivalent stabilizing force of stiffened truss chords
}

\author{
Antoni Biegus ${ }^{1}$, Dariusz Czepiżak ${ }^{1, *}$ \\ ${ }^{1}$ Wrocław University of Science and Technology, Faculty of Civil Engineering, 27 Wybrzeże Wyspiańskiego st., 50-370 Wroclaw, \\ Poland
}

\begin{abstract}
The aim of this paper is research of the equivalent stabilizing forces of the braced top flange of the truss. The study takes into account the initial bow imperfection $e_{0}$ of the braced top flange and the imperfection consisting in a twist of the roof girder's principal plane by angle $\phi_{0}(x)$. Moreover, axial force $N_{3}(x)$ in the top flange of the truss is assumed to be longitudinally parabolically variable. The values of the axial forces is: $N_{\text {supp }}$ - in the support zone of the truss and $N_{\text {span }}$ - in the central zone of truss. As part of this study parametric analyses of the equivalent stabilizing forces and the stress of the bracings depending on axial forces $N_{\text {supp }}$ and $N_{\text {span }}$ in the braced member were carried out. The results are compared with the results of numerical analyses of $3 \mathrm{D}$ models taking the geometric nonlinearity of the structure into account.
\end{abstract}

\section{Introduction}

Bracings are used to stiffen roof (truss or solid) girders in the roof plane. The principles for their use were established on the basis of long time experience. But the calculation of the loads of bracings was theoretically validated using an "imperfect" analytical model of the (with initial bow imperfection) braced member as late as in the last twenty years of the 20th century [1-4]. The "imperfect" model for calculating bracings is recommended in EN 1993-1-1 [1]. The model is based on the following assumptions:

1. The girder flange and the bracing are considered as respectively a beam and a truss, both isolated from the structure. They are connected together by purlins.

2. Initial bow imperfection $e_{0}$ of the braced girder is parabola-shaped in the roof plane.

3. The braced member is stressed by a compressive force which is constant along its length.

4. The twist of the girder's principal plane due to the bow imperfection of its braced top flange is not taken into account in the analysis.

In the case of braced roof girder flanges, the EN 1993-1-1 computational model is not precise [5-7]. The flanges are stressed longitudinally by a variable axial force and so do not satisfy assumption 3. Neither is assumption 4 satisfied since the girder's principal plane is twisted by angle $\phi_{0}$ due to the initial bow imperfection of the braced top flange. Therefore a new generalized model for calculating the equivalent stabilizing force of braced members longitudinally compressed by a variable axial force is proposed here. The model takes into account also the equivalent stabilizing forces generated by the imperfection consisting in the twist of the girder's principal plane by angle $\phi_{0}$. The proposed computational models enable the analysis of the stress of purlins and bracings caused by the equivalent stabilizing force of the real braced flanges of roof girders.

The aim of this paper is to identify the equivalent stabilizing forces of the braced top flange of the roof truss girder. The study takes into account the initial bow imperfection $e_{0}$ of the braced top flange and the imperfection consisting in a twist of the roof girder's principal plane by angle $\phi_{0}(x)$. Moreover, compressive axial force $N_{3}(x)$ in the top flange of the girder is assumed to be longitudinally parabolically variable and to have a distribution as shown in Fig. 1d, e. The values of the compressive axial forces in the support zone $\left(N_{\text {supp }}\right)$ and in the central zone $\left(N_{\text {span }}=N_{E d \text {, } \max }\right)$ of the braced top flange of the girder depend on the load parameters $\left(P_{E d}, w_{p}, w_{n}\right)$. As part of this study parametric analyses of the equivalent stabilizing forces and the stress of the purlins and the bracings depending on axial forces $N_{\text {supp }}$ and $N_{\text {span }}$ in the braced member were carried out. The results are compared with the results of numerical analyses of 3D models taking the geometric nonlinearity of the structure into account.

\section{Analytical determination of equivalent stabilizing force due to initial bow imperfection $e_{0}$ of braced member parabolically compressed by longitudinally variable axial force}

According to EN 1993-1-1 [1], an evaluation of the loading capacity of frame systems and bracings should take

* Corresponding author: dariusz.czepizak@pwr.edu.pl 
into account the forces due to random initial bow imperfections with amplitude $e_{0}$. In calculations the forces are replaced with equivalent stabilizing force $q_{d 1}$ and $R_{d 1}$ determined from the formulas

$$
\begin{gathered}
q_{d 1}=8 N_{E d, \text { max }} \frac{e_{0}}{L^{2}}, \\
R_{d 1}=-4 N_{E d, \text { max }} \frac{e_{0}}{L},
\end{gathered}
$$

where:

$N_{E d \text {,max }}$ - the axial force in the braced member,

$e_{0}-$ the maximum amplitude of the braced member imperfection,

$L-$ the span of the braced member.

Uniformly distributed imperfect span equivalent stabilizing force $q_{d 1}=$ const. acc. to (1) and support reactions $R_{d 1}$ acc. to (2) were determined assuming that the braced member is compressed by force $N_{1}(x)=N_{E d \text {,max }}$, constant along its length.

It should be noted that in the case of the equivalent stabilizing force of the braced top flanges of roof girders the assumption $N_{1}(x)=$ const. is incorrect since it does not correspond to the actual longitudinally variable distribution of the axial force in the braced member. The axial force usually changes parabolically or stepwise parabolically (Fig. 1d), and also its sign can change (compression and tension occur) [6].

a)

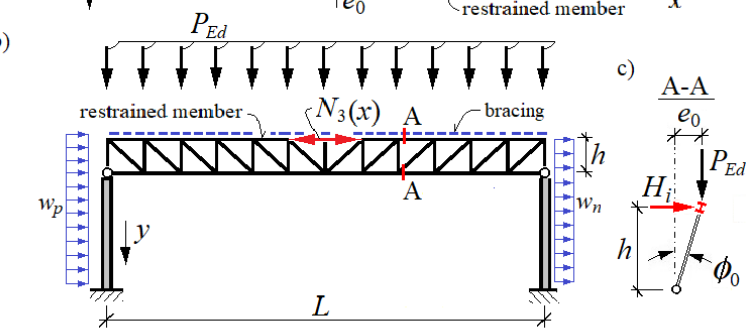

d)
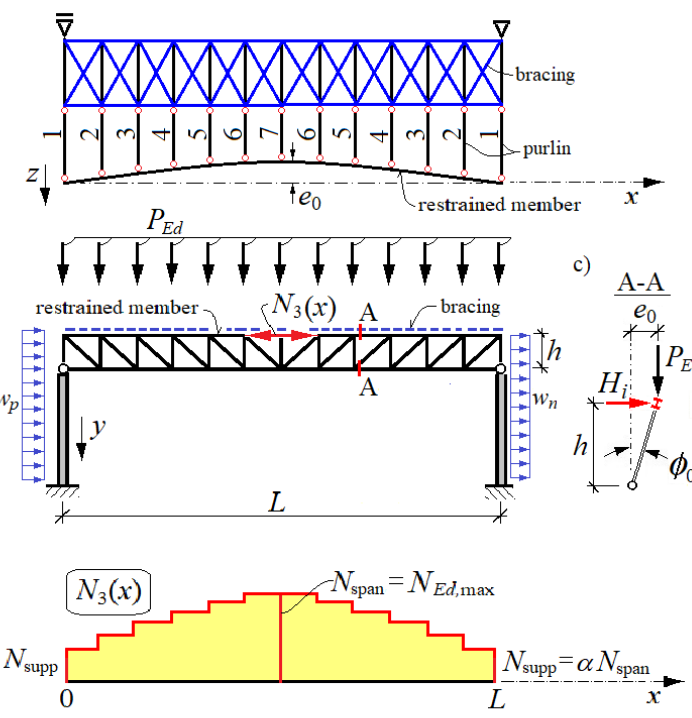

e)

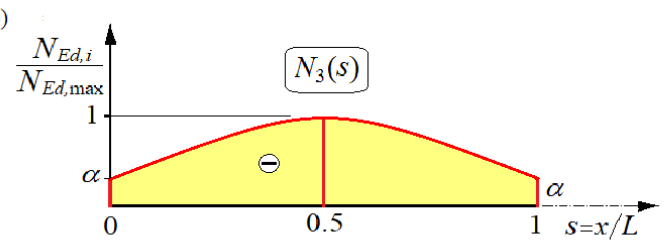

f)

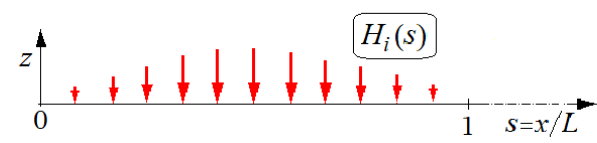

Fig. 1. Schemes of: a) bracing, b) roof girder to columns pin joint, c) twist of truss principal plane, d), e) distribution of the axial force in the restrained upper flange of the roof girder, f) horizontical forces $H_{i}$ due to the distorsion of the truss.
Figure 1b show the loading diagram of the transverse system of steel industrial sheds in which the roof girder is pin jointed with the columns. Due to the overhead wind loads $\left(w_{p}, w_{n}\right)$ axial force $N_{\text {supp }}$ is transferred to the braced top flange of the roof girder. This force and the parabolically longitudinally variable axial force in the top flange generated by the roof girder's equivalent stabilizing force $\left(P_{E d}\right)$ add up. In the considered case, axial force $N_{3}(x)$ changes parabolically along the length of the braced top flange of the roof girder, as shown in Fig. 1d. In the support zone compressive force $N_{3}(0)=N_{\text {supp }}$, whereas in the central zone $N_{3}(0.5 L)=N_{\text {span }}=N_{E d \text {, max }}$.

The longitudinally stepwise parabolically variable distribution of the axial force in the braced top chord of the truss (Fig. 1d) can be approximated with the continuous distribution shown in Fig. 1e. The equivalent stabilizing force of the braced member compressed with axial force distributed according to Fig. 1e was analysed. Extreme axial force $N_{3}(x)$ in the middle of its span $N_{\text {span }}=N_{E d, \max }$ and axial force in the support zone is $N_{\text {supp }}=\alpha N_{E d, \max }$.

General formulas for span equivalent stabilizing force $q(s)$ and support reactions $R_{d}$ of a member loaded by longitudinally variable axial force $N(s)$ with any distribution $N_{E d}(0) \neq N_{E d}(0.5) \neq N_{E d}(1)$ were derived in [5].

If axial force $N_{3}(s)$ varies longitudinally as in Fig. 1e and its extreme value occurs at the midspan of the braced member: $N_{3}(0.5)=N_{\text {span }}=N_{E d \text {, max }}$, span equivalent stabilizing force $q_{d 3}(s)$ and support reactions $R_{d 3}$ are calculated from the formulas

$$
\begin{gathered}
q_{d 3}(s)=8 \frac{e_{0}}{L^{2}} N_{E d, \text { max }}\left[3 \alpha(1-2 s)^{2}-2\left(6 s^{2}-6 s+1\right)\right], \\
R_{d 3}=-4 \alpha \frac{e_{0}}{L} N_{E d, \text { max }},
\end{gathered}
$$

where:

$N_{E d \text {,max }}$ - the value of the extreme axial force at the midspan of the braced member,

$\alpha$ - a dimensionless coefficient of the axial force (Fig. 1e) at respectively the left and right end of the braced member, assuming values from the $\langle 0,1\rangle$ interval (a "+" value - compression),

$s=x / L-$ the relative location (Fig. 1e) of the considered cross section along the length of the braced member, assuming values from the $\langle 0,1\rangle$ interval.

Parametric analyses of equivalent stabilizing forces $q_{d 3}(s), R_{d 3}(s)$ of braced members longitudinally stressed by variable distributions of axial force $N_{3}(s)$ were carried out. The values of coefficient $\alpha$ for the analysed 11 schemes of the longitudinal variation of axial force $N_{3}(s)$ in the braced members are $\alpha=1.0,0.9,0.8,0.7,0.6,0,5$, $0.4,0.3,0.2,0.1,0$.

The distributions of span equivalent stabilizing force $q_{d 3}(s)$ resulting from the stress of the braced member consistently with the considered schemes of axial force $N_{3}(s)$ are shown in Fig. 2a. Figure 2b shows support reactions $R_{d 3}$ of the compressed members versus $\alpha$, corresponding to the considered diagrams of axial forces $N_{3}(s)$. 
An analysis of the parametric calculations indicates that the parabolic distribution of span equivalent stabilizing force $q_{d 3}(s)$ corresponds to the parabolic distribution of axial force $N_{3}(s)$ in the braced member.

a)

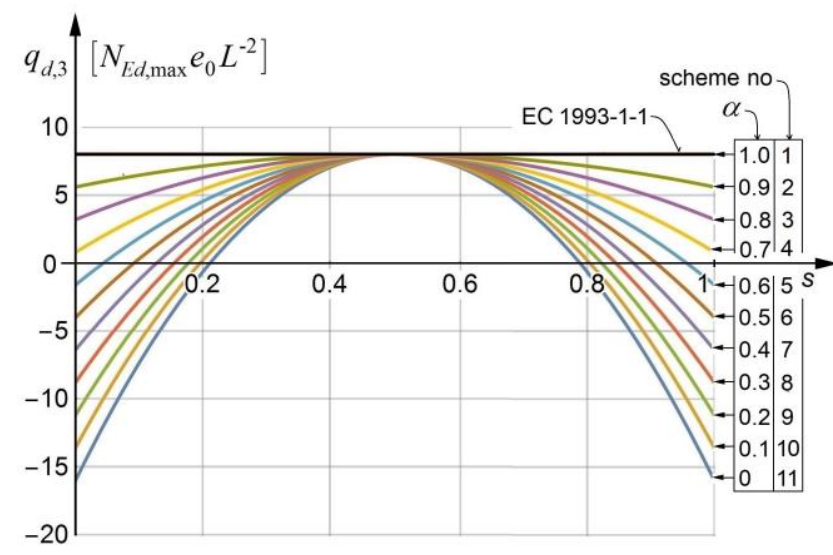

Span equivalent stabilizing force $q_{d 3}(s)$ and support reactions $R_{d 3}$ in the analysed diagrams of the longitudinal stress of the brace members are a linear function of dimensionless axial force parameter $\alpha$.

b)

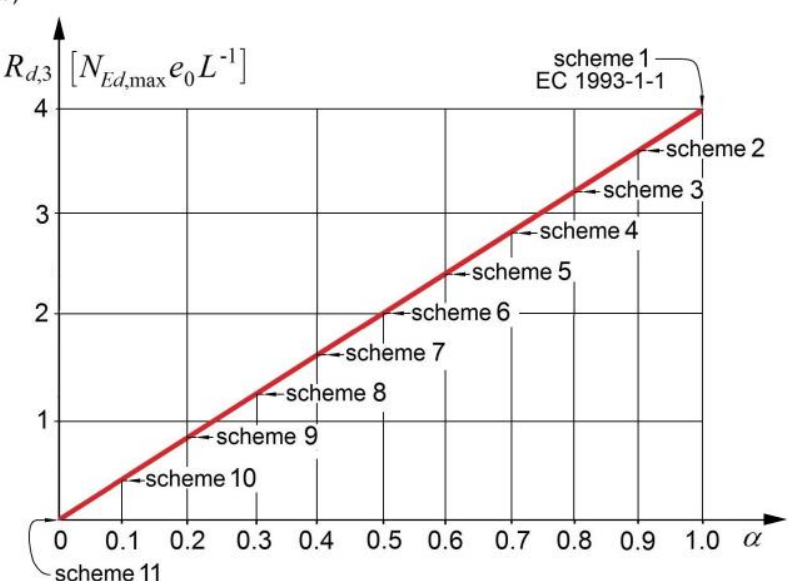

Fig. 2. Distributions of: a) equivalent stabilizing force $q_{d 3}(s)$ in restrained members as a function of parameter $\alpha$, b) support reactions $R_{d 3}$ in restrained members as a function of parameter $\alpha$.

Equivalent stabilizing force $q_{d 3}(x)$ differs fundamentally from $q_{d 1}$ (Fig. 2a), the consequence of which is a significant difference between the evaluated reliability of the purlins and the bracing [5-7] and the one calculated acc. to EN 1993-1-1 [1].

The equivalent stabilizing forces of the braced member consists of span force $q_{d 3}(s)$ (Fig. 2a) and support reactions $R_{d 3}$ (Fig. 2b). Equivalent stabilizing force $q_{d 3}(s)$ and support reactions $R_{d 3}$ together form a selfequilibrating system. Whereas in the case of the equivalent force of the member acc. to scheme $11(\alpha=0)$ there is no support reaction $\left(R_{d 3}=0\right.$, see Fig. $\left.2 \mathrm{~b}\right)$. Then span equivalent stabilizing force $q_{d 3}(s)$ is self-equilibrating along the length of the braced member.

Span equivalent stabilizing force $q_{d 3}(s)$ (Fig. 2a) is variable (nonuniform) along the length of the braced member and when $\alpha<0.65$, it is also longitudinally sign-variable.

If $\alpha<0.3$, then the highest equivalent stabilizing force $q_{d 3}(0)=q_{d 3}(1)$ occur in the support zones of the braced members (Fig. 2a). Moreover, when $\alpha<0.3$, equivalent force $q_{d 3}(0.5)$ in the central zone have opposite senses and are lower than $q_{d 3}(0)$ and $q_{d 3}(1)$ (Fig. 2a). For example, in the case of scheme $11(\alpha=0)$, the equivalent stabilizing force in the support zone of the braced member: $q_{d 3}(0)=q_{d 3}(1)=16 q$ (where $q=$ $\left.N_{E d, \text { max }} e_{0} L^{-2}\right)$ is twice as high as the equivalent force at midspan: $q_{d 3}(0.5)=8 q$ (Fig. 2a). It should also be noted that support equivalent stabilizing force $q_{d 3}(0)=q_{d 3}(1)=$ $16 q$ is twice as high as equivalent stabilizing force $q_{d 1}=$ $8 q$ calculated acc. to EC 1993-1-1 [1].

A comparison of equivalent stabilizing forces $q_{d 1}$ and $q_{d 3}(s)$ clearly indicates that their estimates acc. to EN 1993-1-1 [1] differ fundamentally from the ones acc. to the adopted model. The differences are both qualitative and quantitative. This has a significant bearing on the stress of both the purlins and the bracings.
Total span equivalent stabilizing force $q_{d 3, m}(s)$ and support reactions $R_{d 3, m}$ from $m$ braced members, with the bracing deformation taken into account, is calculated from the formulas

$$
\begin{gathered}
q_{d 3, m}(s)=8\left[3 \alpha(1-2 s)^{2}-2\left(6 s^{2}-6 s+1\right)\right] \frac{e+\delta_{q, w}}{L^{2}} \sum_{j=1}^{m} N_{E d, \max , j} \\
R_{d 3, m}=-4 \alpha \frac{e+\delta_{q, w}}{L} \sum_{j=1}^{m} N_{E d, \text { max }, j}
\end{gathered}
$$

where:

$\delta_{q, w}$ - the midspan deflection of the bracing under equivalent stabilizing force $q_{d 3}$ and all the other external loads, obtained from the 1st order analysis (when the 2 nd order theory is used to analyse the structure, one can assume $\delta_{q, w}=0$ ),

$m$ - the number of braced members,

$e$ - the total amplitude of $m$ braced members imperfection, amounting to

$$
e=\frac{L}{500} \sqrt{0,5\left(1+\frac{1}{m}\right)} .
$$

The equivalent axial forces in the principal purlins $\left(F_{d 1, i, m}\right)$, determined using the computational model contained in EN 1993-1-1 [1] (when $N_{1}=$ const.), have identical values and the same sense (since $q_{d 1}=$ const.). In the case of schemes 2-11 with parabolic distributions of axial force $N_{3}(s)$, the values of all the equivalent axial forces in the principal purlins $\left(F_{d 3, i, m}\right)$ vary along the length of the braced member. Moreover, if parameter $\alpha<0.5$, also the senses of forces $F_{d 3, i, m}$ change along the length of the braced member.

An approach alternative to the analytical method of determining equivalent stabilizing force due to initial 
bow imperfection $e_{0}$ according (3), (4) consists in analysing the equilibrium of the forces in the joints in which the braced member is connected with a purlin [8].

Knowing (e.g. from the calculations of the internal forces in the truss members) the values of the axial forces in the bow curved braced member (the top flange) one can determine from the condition of the equilibrium of the forces in its joints the particular equivalent forces $F_{d, i}$ transferred to the purlins. In this method the braced member is modelled by a system of single span beams. Their supports are situated consistently with the braced member's bow curvature. The span length of the beams is equal to spacing of the purlins. The beams are loaded with axial force $N(x)$ variable along their length and distributed as in the braced member. The particular spans $i$ of the beams are stressed by variable axial forces $N_{i}$. Support reactions $R_{i}$ of the considered beam system (Fig. 3 ) are the braced member's equivalent horizontal forces $F_{d, i}$ transferred to the purlins and to the bracing. They are calculated from the formula

$$
F_{d, i}=R_{i}=N_{i} \sin \varphi_{i}-N_{i+1} \sin \varphi_{i+1} .
$$

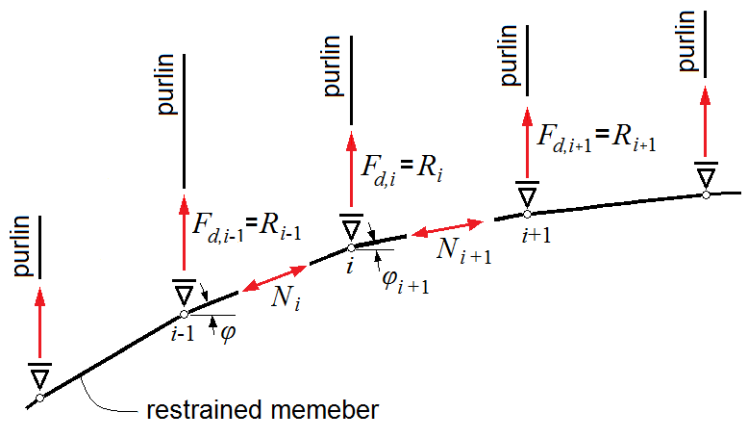

Fig. 3. Scheme of determination of equivalent horizontal forces from the condition of equilibrium of forces grouped in specified nodes.

\section{Equivalent horizontal forces due to twist of truss's principal plane by angle $\phi_{0}$}

In the calculations acc. to EN 1993-1-1 [1] braced top chords are treated as initial bow curved members "isolated" from the truss (not connected via lattice work with the bottom chords). This computational model does not reflect the behaviour and stress of a real truss, i.e. the twist of its principal plane by angle $\phi_{0}$ due to initial bow imperfection $e_{0}$ of the top chord (Fig. 1c) and also the stiffness parameters of its members and joints.

Figure 1c shows initial bow imperfection $e_{0}$ of the truss's top chord in the plane of the roof. Since the top chord is curvilinear while to bottom chord is rectilinear the bow imperfection results in the twist of the principal plane of the truss. Hence besides the initial bow imperfection $y(s)$ of top chord, there is an imperfection consisting in the twist of the truss's principal plane by angle $\phi_{0}(s)$. As a result of the action of vertical loads $P_{E d, i}$ in top joints $i$ on the truss twisted by angle $\phi_{0}\left(s_{i}\right)$ equivalent horizontal forces $H_{i}$ arise. They are transferred to the purlins and to the bracing (Fig. 1a, c), increasing their stress.

Assuming that vertical forces $P_{E d}$ are identical and that only the top chord is bow curved (Fig. 1c), equivalent horizontal forces $H_{i, m}$ in joint $i$ originating from braced $m$ trusses can be estimated using the formula [5]

$$
H_{i, m}=4 \sum_{j=1}^{m} P_{E d, j}\left(e+\delta_{q, H, w}\right) \frac{s_{i}\left(1-s_{i}\right)}{h_{i}},
$$

where:

$\delta_{q, H, w}$ - the midspan deflection of the bracing under equivalent forces $q_{d}$ and $H_{i}$ and all the external loads (e.g. wind load $w$ ), obtained from the 1 st order analysis (if the 2nd order theory is used one can assume $\delta_{q, H, w}=0$ ),

$h_{i}-$ the construction depth of the truss in joint $i$.

In the case of oppositely directed bow imperfections of the top and bottom chords (Fig. 4e), the values of equivalent horizontal forces $H_{i}$ are twice as high as the ones calculated from (9).

The distribution of equivalent horizontal forces $H_{i}$ due to the twist of the principal plane of the truss varies along the length of the latter (Fig. 1f). In the considered case, the distribution is parabolic consistently with the adopted bow imperfection of the axis of the braced member $(y(s))$. The strongest equivalent horizontal force $H_{i}$ occur at the midspan of the truss when $y(0.5)=e_{0}$.

\section{Analysis of total equivalent stabilizing forces due to initial bow imperfection $e_{0}$ of braced flange of girder and twist of its principal plane by angle $\phi_{0}$}

Initial bow imperfection $e_{0}$ of the braced flange and the twist of the principal plane of the girder by angle $\phi_{0}$ together generate equivalent forces transferred to the purlins and the bracing. Therefore when evaluating the equivalent stabilizing forces one should add up the force due to the braced flange bow imperfection $\left(q_{d 3}\right.$ and $\left.R_{d 3}\right)$ and to the twist of the girder $\left(H_{i}\right)$.

In order to quantitatively evaluate the total imperfect effect due to initial bow imperfection $e_{0}$ and to the twist of the principal plane of the truss by angle $\phi_{0}$ on the stress of the purlins and bracing (see Fig. 1a) calculations were done for the truss show in Fig. 1b. The purlins are spaced at every $2.0 \mathrm{~m}$. The span of the girder is $L=12 \times 2 \mathrm{~m}=24 \mathrm{~m}$. Its transverse concentrated load is $P_{E d}=10 \mathrm{kN}$.

The axial force at the midspan of the girder's braced top chord is $N_{\text {span }}=N_{E d \text {,max }}=163.64 \mathrm{kN}$, while the axial force at its support is $N_{\text {supp }}=\alpha N_{E d, \max }=49.42 \mathrm{kN}$ (Fig. 1d), factor $\alpha=0.151$.

The initial bow imperfection of the girder's braced flange is $e_{0}=L / 500=24000 / 500=48 \mathrm{~mm}$.

The diagonals of the bracing are assumed to be thin beams which do not transfer compressive forces.

The results of the calculations are presented in Table 1 
Table 1. Axial forces in purlins due to equivalent stabilizing force $q_{d 3}$ (for $\alpha=0.151$ ) and forces $H_{i}[\mathrm{kN}]$

\begin{tabular}{|c|c|c|c|c|c|}
\hline \multirow{2}{*}{$\begin{array}{c}\text { Member } \\
\text { no }\end{array}$} & \multicolumn{5}{|c|}{ Axial forces from loads [kN] } \\
\cline { 2 - 6 } & $q_{d 1}$ & $q_{d 3}$ & $H_{i}$ & $q_{d 3}+H_{i}$ & $\left(q_{d 3}+H_{i}\right) / q_{d 1}$ \\
\hline 1 & -1.200 & -0.346 & 0 & -0.346 & 0.288 \\
\hline 2 & 0.218 & -0.168 & 0.067 & -0.101 & 0.463 \\
\hline 3 & 0.218 & -0.030 & 0.121 & 0.091 & 0.417 \\
\hline 4 & 0.218 & 0.078 & 0.164 & 0.242 & 1.100 \\
\hline 5 & 0.218 & 0.155 & 0.194 & 0.349 & 1.601 \\
\hline 6 & 0.218 & 0.201 & 0.212 & 0.413 & 1.894 \\
\hline 7 & 0.218 & 0.217 & 0.218 & 0.436 & $\mathbf{2 . 0 0 0}$ \\
\hline \multicolumn{7}{|c|}{ Notation of axial forces: ,+”- compression } \\
\hline
\end{tabular}

The latter contains the values of the axial forces in the purlins (the numbering of the purlins was shown in Fig. 1a) due to the equivalent stabilizing forces generated by one braced truss. The forces in the purlins due to respectively equivalent force $q_{d 3}$ (for $\alpha=0.151$ ) and the equivalent horizontal forces $H_{i}$ (for the truss where only its top chord is initially curved; Fig. 1c) are specified in columns 3 and 4 in Table 1.

In comparison with equivalent stabilizing force $q_{d 1}$ (column 2 in Table 1) acc. to EN 1993-1-1 [1], the total equivalent forces: $q_{d 3}+H_{i}$ (column 5 in table 1 ) causes:

- an increase in the axial forces in the midspan purlins of the braced truss chord, i.e. by $11 \%$ - in purlin $4,60.1 \%$ - in purlin 5, 89.4\% - in purlin 6 and $100 \%$ - in purlin 7 (the middle one);

- a reduction in the axial forces in the support zone of the braced top chord of the truss, i.e. by $71.2 \%$ in purlin 1 (the eaves purlin), $53.7 \%$ - in purlin 2 and $58.3 \%$ - in purlin 3 .

Additional calculations of the bracings loaded with forces $q_{d 3}+H_{i}$ showed a reduction in the forces in the diagonals in the support zone and an increase in the forces in the diagonals in the central zone of the bracing (from $18.4 \%$ to $48.7 \%$ ).

\section{Numerical analysis of equivalent stabilizing forces of spatial roof structure mode}

The models for computing equivalent stabilizing force, presented in sections 2-4, apply to a braced girder flange parabolically compressed by a longitudinally variable axial force and having initial bow imperfection $e_{0}$, which is "isolated" from the structure, and to the effects of the twist of the girder's principal plane by angle $\phi_{0}$. In these computational models in order to explain how equivalent stabilizing force are generated the latter are separated into forces caused by initial bow imperfection $e_{0}$ of the braced flange and forces resulting from the twist of the girder's principal plane by angle $\phi_{0}$.

It is obvious that the equivalent forces add up interactively and so an evaluation of the equivalent stress should take the nonlinearity of the structure into account. Moreover, equivalent stabilizing forces depend on the design of the girders and the bracings as well as on the stiffness parameter of their members, joints and connections. Besides random initial bow imperfection $e_{0}$ of the braced top flange of the girder one should also take into account the bow imperfection of its bottom flange (Fig. $4 \mathrm{~b}-\mathrm{e})$. Therefore in the general case, when determining the equivalent stabilizing force of braced girders one should use the GMNA/GMIA analysis of a 3D model, adopting the actual stiffnesses of the structure's members and joints.

A numerical analysis of the internal forces in the spatial roof structure shown in Fig. 4 was carried out. The geometry, loads and initial bow imperfection $e_{0}$ of the truss and the geometry of the purlins and the bracing were assumed as in section 4 (Fig. 1a and Fig. 4a). The truss's diagonals and verticals were assumed to be rigidly connected together in both directions by the continuous chords.

The equivalent stabilizing forces generated in the spatial structure (Fig. 4) by the braced top chord of the truss (along axis A in Fig. 4a) were numerically determined. The equivalent axial forces in the purlins, determined using geometrically linear elastic analysis LIA (acc. to the 1st order theory) and geometrically nonlinear elastic analysis GNIA (acc. to the 2nd order theory), are given in Table 2.

As part of the numerical analyses the effect of a random geometry of the truss top and bottom flange bow imperfection and that of the way of stiffening the lateral bottom flange were studied model 0 and models 1-4 shown in Fig. 4b-e.

In model 0 the truss's bottom chord is rectilinear. All the joints of the truss's bottom chord are fixed laterally (rows 4 and 5 in Table 2). The model was studied in order to verify the analytical solution presented in section 4 (row 3 in Table 2) for the $q_{d 3}+H_{i}$ load diagram (column 5 in Table 1). A comparison of the forces in the purlins determined acc. to the analytical model for equivalent stabilizing force $q_{d 3}+H_{i}$ and the ones calculated using numerical model 0 shows that the estimation of the equivalent force presented in sections 2-4 is correct in the light of the model calculation assumptions. The differences between the analytically determined forces in the purlins (row 3 in Table 2) and the ones obtained numerically (rows 4 and 5 in Table 2) are due to, among other things, the discrepancy between the values of the axial force in the support zone of the models and also to the use of a truss brace (diagonals 15 and 16, Fig. 4a) in the support zone in the numerical model.

In model 1 the rectilinear bottom chord is laterally stiffened with a truss brace at the midspan of the truss (Fig. 4b, rows 6 and 7 in Table 2). In models 2, 3 and 4 (Fig. 4c-e) the bottom flanges are not laterally braced. In model 2 the bottom chord is rectilinear (Fig. 4c, rows 8 and 9 in Table 2). In model 3 the bottom chord is bow curved identically as the top chord (Fig. 4 d, rows 10, 11 in Table 2). In model 4 the bow imperfections of the top and bottom chords are sign-variable (Fig. 4e, rows 12, 13 in Table 2).

The following conclusions can be drawn from the results presented in Table 2 . 
- A comparison of the results of respectively the linear and nonlinear analysis, i.e. of rows 4, 6, 8, 10 and 12 (LIA) with rows 5, 7, 9, 11 and 13 (GLIA) in Table 2 indicates that there are significant differences between the values of the axial forces generated by the equivalent stabilizing forces. The differences are due to, among other things, the displacement of the lateral unbraced bottom chord (see values $\underline{u}_{y}$ in Table 2) and the twist of the principal plane of the truss. Therefore the nonlinear analysis of a 3D model of the structure should be used to evaluate the equivalent stabilizing forces.

- The numerical analysis of the 3D model showed that when the top chord is bow curved and the bottom chord is rectilinear (model 2, rows 8,9 in Ta- ble 2), and also in the case of the sign-variable bow imperfection of the bottom chord (model 4, rows 12,13 in Table 2), much stronger (in comparison with the analytical estimate for equivalent forces $q_{d 3}+H_{i}$; row 3 in Table 2) forces reliable for dimensioning purlins arise (in the central zone of the braced chord).

- The numerical studies of models 0-4 have confirmed that when identifying the equivalent stabilizing forces adopted in the computational models proposed in sections 2-4 not only the effects of initial bow imperfection $e_{0}$, but also the actual distribution of the longitudinal variation of the axial forces in the girder's braced top flange and the twist of the girder's principal plane should be taken into account.

a)

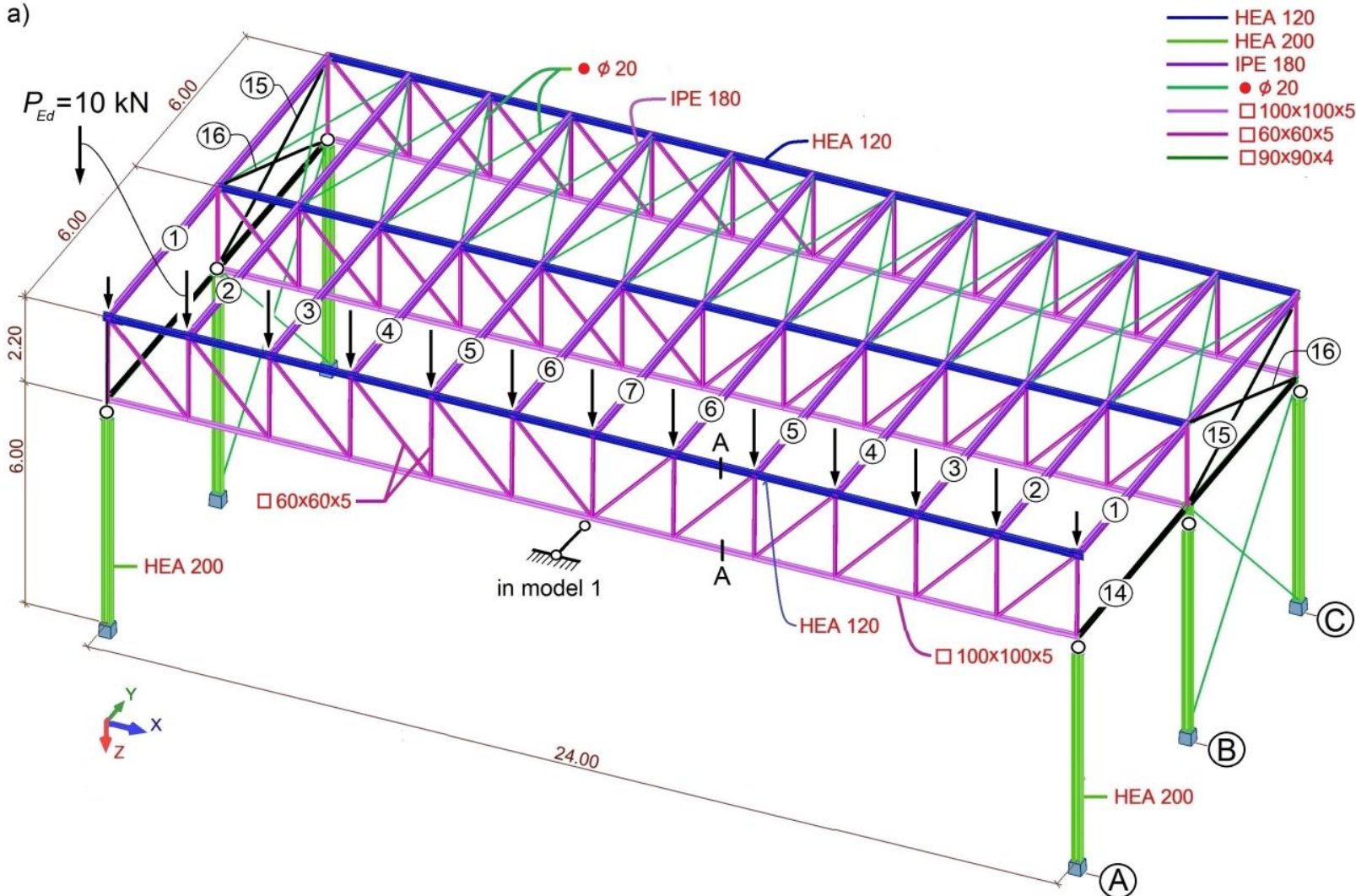

b)

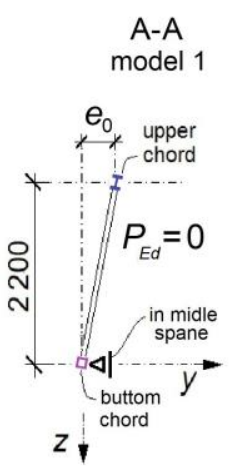

c)

$$
\text { A-A }
$$

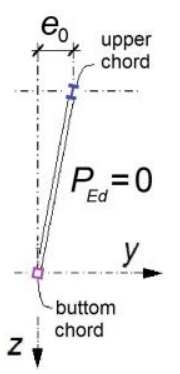

d)

$$
\begin{gathered}
\text { A-A } \\
\text { model } 3
\end{gathered}
$$

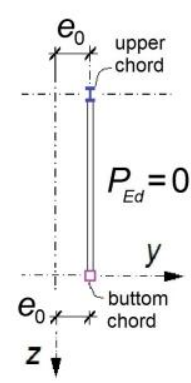

e)

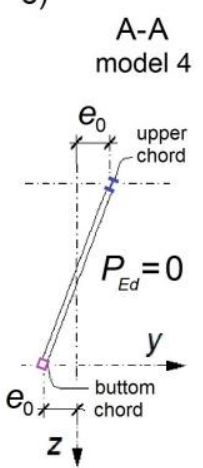

f)

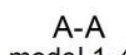

model $1-4$

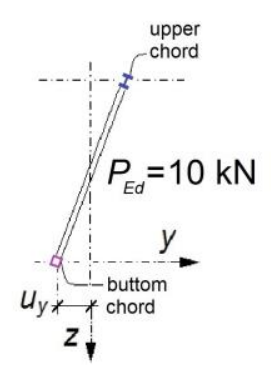

Fig. 4. Spatial model of roof structure: a) numerical model of structure, b)-f) models of imperfections of truss's top and bottom chords. 
Table 2. Results of numerical analyses of spatial roof structure.

\begin{tabular}{|c|c|c|c|c|c|c|c|c|c|c|c|}
\hline \multirow{2}{*}{1} & \multirow{2}{*}{\multicolumn{3}{|c|}{ Analysis model }} & \multicolumn{7}{|c|}{ Axial forces in purlins (strut no - Fig. 1a and 3a) $[\mathrm{kN}]$} & \multirow{3}{*}{$\begin{array}{c}u_{y} \\
\text { (Fig. 4f) } \\
\text { [mm] }\end{array}$} \\
\hline & & & & 1 & 2 & 3 & 4 & 5 & 6 & 7 & \\
\hline 2 & \multirow{2}{*}{\multicolumn{2}{|c|}{ analytical }} & $q_{d 1}$ & -1.200 & 0.218 & 0.218 & 0.218 & 0.218 & 0.218 & 0.218 & \\
\hline 3 & & & $q_{d 3}+H_{i}$ & -0.346 & -0.101 & 0.091 & 0.242 & 0.349 & 0.413 & 0.436 & - \\
\hline 4 & \multirow{10}{*}{ 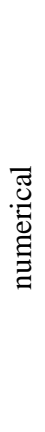 } & \multirow{2}{*}{ model 0} & LIA & -0.349 & -0.120 & 0.096 & 0.248 & 0.357 & 0.418 & 0.432 & 0 \\
\hline 5 & & & GLIA & -0.352 & -0.122 & 0.098 & 0.254 & 0.367 & 0.430 & 0.445 & 0 \\
\hline 6 & & model 1 & LIA & -0.073 & -0.295 & -0.040 & 0.146 & 0.344 & 0.515 & 0.538 & 0 \\
\hline 7 & & (Fig. 4b) & GNIA & -0.227 & -0.322 & 0.039 & 0.237 & 0.395 & 0.509 & 0.523 & 0 \\
\hline 8 & & model 2 & LIA & 0.309 & -0.333 & -0.043 & 0.110 & 0.267 & 0.358 & 0.398 & -32.7 \\
\hline 9 & & (Fig. 4c) & GNIA & -0.005 & -0.510 & -0.003 & 0.222 & 0.414 & 0.509 & 0.540 & -24.1 \\
\hline 10 & & model 3 & LIA & 0.860 & 0.081 & 0.029 & 0.000 & 0.008 & 0.012 & 0.079 & -57.6 \\
\hline 11 & & (Fig. 4d) & GNIA & 0.438 & -0.338 & 0.010 & 0.108 & 0.223 & 0.280 & 0.329 & -38.1 \\
\hline 12 & & model 4 & LIA & -0.243 & -0.585 & -0.115 & 0.221 & 0.526 & 0.705 & 0.716 & -7.7 \\
\hline 13 & & (Fig. 4e) & GNIA & -0.447 & -0.682 & -0.015 & 0.336 & 0.605 & 0.737 & 0.750 & -10.2 \\
\hline
\end{tabular}

- The equivalent stabilizing force of compression members are commonly considered to be an important factor to be taken into account in analyses of the stress of structural members. The analyses carried out in this paper have shown that the tension members (model 4) and also the tension zones of the braced girders [6] generate equivalent stabilizing forces similarly as the compression members. Their values can be higher than the ones calculated acc. to [1]. For example, when the random bow imperfection of the tension bottom chord (model 4, rows 12, 13 in Table 2) is taken into account, the equivalent stabilizing forces increase in comparison with model 2 without the bottom chord bow imperfection (model 2; rows 8 , 9 in Table 2).

- If the same initial bow imperfection $e_{0}$ is assumed for both the top and bottom flange of the girder (model 3, rows 10, 11 in Table 2), the imperfect forces in the purlins are weaker (relative to models $0,1,2,4)$.

- Both the numerical studies of models 0, 1, 2, 4 and the calculations done acc. to the proposed analytical models (presented in sections 2-4) have shown that the axial forces reliable for dimensioning purlins occur in the middle purlin (rows 3-9, 12, 13 in Table 2) and not in the eaves purlin as indicated by the calculations done acc. to EC $1993-1-1$ [1] (row 2 in Table 2).

\section{Conclusions}

If the real parabolic distribution of the axial force in the braced member is adopted in the computational model, the equivalent stabilizing force and the axial forces in the bracing's purlins and members differ both qualitatively and quantitatively from the ones yielded by the model recommended by EN 1993-1-1 [1]. The parametric analysis of the stress of the purlins and the bracing diagonals carried out in section 2-5 clearly shows that by disregarding the real distribution of the axial force in the braced member one will incorrectly assess of their reliability.

For all the diagrams 2-11 as the support axial force decreases $S_{\text {supp }}(\alpha<1)$, the axial forces in all the purlins decrease (in comparison with the ones calculated acc. to EN 1993-1-1 [1]). In the central zone this decrease is only slight. Also the axial force values reliable for dimensioning purlins decrease (relative to the ones calculated acc. to EN 1993-1-1 [1]. As a result, the axial forces in the diagonals decrease (relative to the ones calculated acc. to EN 1993-1-1 [1]) and the axial force values reliable for dimensioning the bracing also decrease.

The equivalent axial forces in the principal purlins $\left(F_{d 1, i, m}\right)$, determined using the computational model contained in EN 1993-1-1 [1] (when $N_{1}=$ const.), have identical values and the same sense (since $q_{d 1}=$ const.). In the case of schemes 2-11 with parabolic distributions of axial force $N_{3}(s)$, the values of all the equivalent axial forces in the principal purlins $\left(F_{d 3, i, m}\right)$ vary along the length of the braced member. Moreover, if parameter $\alpha<0.5$, also the senses of forces $F_{d 3, i, m}$ change along the length of the braced member.

The "imperfect" model in EN 1993-1-1 [1] is limited to an analysis of the effects of initial bow imperfection $e_{0}$ of the braced top flange of the girder. However, the consequence of the top flange bow imperfection is the twist of girder's principal plane by angle $\phi_{0}$, which generates equivalent horizontal forces $H_{i}$. The latter are transferred to the purlins and to the bracing, increasing their stress. The computational model in EN 1993-1-1 [1] does not take into account equivalent horizontal forces $H_{i}$ caused by the twist of the truss.

The distribution of equivalent horizontal forces $H_{i}$ due to the twist of the principal plane of the truss varies along the length of the latter. In the considered case, the distribution is parabolic consistently with the adopted bow imperfection of the axis of the braced member $[y(s)]$. The strongest equivalent horizontal force $H_{i}$ occur at the midspan of the truss when $y(0.5)=e_{0}$. 
In order to explain the physics of the stress of the structure and the generation of equivalent stabilizing forces the latter in the analysed models were separated into loads due to initial bow imperfection $e_{0}$ of the braced flange and loads due to the twist of the girder's principal plane. However, the effects of these loads add up. When determining the total equivalent stabilizing force one can use the nonlinear geometric analysis of the 3D computational beam model, taking into account the real stiffnesses of the members and joints of the considered structure.

In comparison with equivalent stabilizing force $q_{d 1}$ acc. to EN 1993-1-1 [1], the total equivalent forces: $q_{d 3}+H_{i}$ causes: an increase in the axial forces in the midspan purlins of the braced truss chord and a reduction in the axial forces in the support zone of the braced top chord of the truss.

Additional calculations of the bracings loaded with forces $q_{d 3}+H_{i}$ showed a reduction in the forces in the diagonals in the support zone and an increase in the forces in the diagonals in the central zone of the bracing in comparison to EN 1993-1-1 [1] model.

The equivalent stabilizing force of compression members are commonly considered to be an important factor to be taken into account in analyses of the stress of structural members. The analyses carried out in this paper have shown that the tension members (model 4) and also the tension zones of the braced girders [5-7] generate equivalent stabilizing forces similarly as the compression members. Their values can be higher than the ones calculated acc. to EN 1993-1-1 [1]. For example, when the random bow imperfection of the tension bottom chord (model 4, rows 12, 13 in Table 2) is taken into account, the equivalent stabilizing forces increase in comparison with model 2 without the bottom chord bow imperfection (model 2; rows 8, 9 in Table 2).

The numerical studies of models $0-4$ have confirmed that when identifying the equivalent stabilizing forces adopted in the computational models proposed in sections 2-6 not only the effects of initial bow imperfection $e_{0}$, but also the actual distribution of the longitudinal variation of the axial forces in the girder's braced top flange and the twist of the girder's principal plane should be taken into account.

The quantitative and qualitative differences between the proposed computational models and the evaluation acc. to EN 1993-1-1 [1] are considerable. Therefore one should consider introducing (after additional numerical analyses) proper corrections pertaining to the investigated problem in the revised EN 1993-1-1 [1].

\section{References}

1. EN 1993-1-1, Eurocode 3: Design of Steel Structures. Part 1-1: General Rules and Rules for Building.

2. M. Gardner, D. Nethercot, in: H. Gulvanessian (Eds.) Designers Guide to EN 1993-1-1: Eurocode 3 Design of Steel Structures. Part 1-1: General Rules and Rules for Building, Thomas Telford Limited, London, 2005.
3. J.C Taylor, et all, Interim Guidance on the Use of Eurocode 3: Eurocode 3 Part 1-1: for European Design of Steel Building Structures, The Steel Construction Institute, Ascot, 1995.

4. N.S. Trahair, M.A. Bradford, D.A. Nethercot, L. Gardner, The Behaviour and Design of Steel Structures to EC3, Taylor and Francis, London-New York, (2008).

5. D. Czepiżak, A. Biegus, Refined calculation of lateral bracing systems due to global geometrical imperfections, Journal of Constructional Steel Research, 119 (2016).

6. A. Biegus, D. Czepiżak, Imperfection force of members under longitudinal action having a variable sign, EUROSTEEL 2017, September 13-15, 2017, Copenhagen Denmark, 1, 2/3 (2017).

7. A. Biegus, D. Czepiżak, Generalized model of imperfection forces for design of transverse roof bracings and purlins, Archives of Civil and Mechanical Engineering, 18 (2018).

8. Sz. Pałkowski, M. Piątkowski, On the calculation of lateral roof bracing, Inżynieria i Budownictwo, 4 (2014) [in Polish]. 